\title{
Miyelodisplastik Sendrom Hastalarının Akan Hücre Ölçer ile Yapılan Ogata Skorlaması Yoluyla Değerlendirilmesi: Pilot Çalışma
}

\author{
Evaluation of Patients With Myelodysplastic Syndrome \\ by Ogata Scoring in Flow Cytometry: Pilot Study
}

Erden ATilla ${ }^{1} \mathbb{D}$, Ekin $\operatorname{KIRCALI}^{1} \mathbb{D}$, Pınar ATACA ATilla ${ }^{1} \mathbb{D}$, Sinem Civriz BOZDAĞ ${ }^{1} \mathbb{D}$,

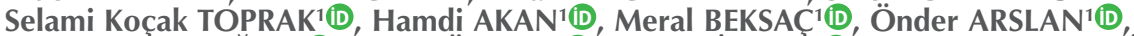

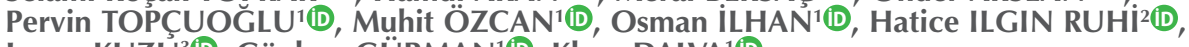

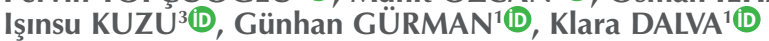

1 Ankara Üniversitesi Tıp Fakültesi, Hematoloji Bilim Dalı, Ankara, Türkiye

2 Ankara Üniversitesi Tıp Fakültesi, Tıbbi Biyoloji ve Genetik Anabilim Dalı, Ankara, Türkiye

${ }^{3}$ Ankara Üniversitesi Tıp Fakültesi, Tıbbi Patoloji Anabilim Dalı, Ankara, Türkiye

öz

Amaç: Dünya Sağlık Örgütü, myelodisplastik sendromları (MDS) kemik iliği displazilerine göre sınıflamaktadır. Akan Hücre Ölçer, hematolojik malignensilerin tanısında ve takibinde önem taşımaktadır. Ogata ve arkadaşları kemik iliği displazisinin gösterilemediği hastalarda tanıyı kolaylaştırmak amacıyla akan hücre ölçer ile bir skorlama sistemi geliştirmiştir. Bu çalışmada, merkezimizde MDS ön tanısıyla biyopsi yapılan hastalada patolojik olarak MDS tanısını almalarından sonra akan hücre ölçer ile yeniden skorlanması ve sonuçların değerlendirilmesi amaçlanmıştır.

Hastalar ve Yöntem: Merkezimizde 2015 yılında sitopenisi olan 386 hastaya MDS ön tanısıyla kemik iliği biyopsisi yapılmış ve 78 hasta (\%20) patolojik olarak MDS tanısı almıştır. Hastalar akan hücre ölçer ile dört parametrenin kombine edildiği bir skorlama sistemi ile yeniden değerlendirilmiştir: Artmış myeloblast oranı (CD34+ olanların oranı > \%2), azalmış CD34+B progenitör oranı (Total CD34 + hücrelerin \%5'inden az), lenfositlerin CD45 ifadesi ile oranlandığında oranda artma ya da azalma $(<4,>7.5)$ ve granülositlerin verdiği $90^{\circ}$ ışık dağılımında azalma (granülosit/lenfosit SSC oranı <6). Skorun 2 ve üzerinde olması durumu MDS tanısını desteklemektedir. Kategorik değişkenlerin analizinde Ki-kare testi kullanılmıştır.

Bulgular: 78 hastanın ortanca yaşı 62'dir. Kemik iliği displazisinin özgün göstergelerinin (ör. Ring sideroblast ve/veya klonal kromozomal anormallikler) olmadığı düşük risk hastalarda (\%45) Ogata skoru iki veya üzerindedir. Ogata skoru yüksek bulunan hastaların (Skor 3 veya 4) transfüzyon bağımlısı olduğu $(p=0.021)$ ve WPSS skorunun daha yüksek olduğu saptanmıştır $(p=0.002)$.

Sonuç: Akan hücre ölçer ile belirlenen Ogata skoru, MDS hastalarının tanısında kullanılabilecek bir yöntem olarak değerlendirilmiştir

Anahtar Kelimeler: Myelodisplastik sendromlar; Akan hücre ölçer; Ogata skoru

\section{ABSTRACT}

Objective: World Health Organization classifies myelodysplastic syndromes (MDS) according to bone marrow dysplasia. Flow Cytometry is important in the diagnosis and follow-up of hematological malignancies. Ogata et al. developed a scoring system for flow cytometry in order to facilitate diagnosis in patients in whom bone marrow dysplasia can not be demonstrated. In this study, it was aimed to use the scoring system in pathologically proven MDS patients who underwent biopsy with a pre-diagnosis of MDS in our center and evaluate the results.

Makale atıfı: Atilla E, Kırcalı E, Ataca Atilla P, Civriz Bozdağ S, Toprak SK, Akan $\mathrm{H}$ ve ark. Miyelodisplastik sendrom hastalarının akan hücre ölçer ile yapılan ogata skorlaması yoluyla değerlendirilmesi: pilot çalışma. LLM Dergi 2020;4(3):45-9.

\section{Yazıșma Adresi}

\section{Doç. Dr. Erden ATíLA}

Ankara Üniversitesi Tıp Fakültesi, Hematoloji Bilim Dalı,

Ankara-Türkiye

Geliş: 10.09.2020 - Kabul: 19.10.2020

E-posta: erdenatilla@gmail.com 
Patients and Methods: In our center, bone marrow biopsy was performed on 386 patients with cytopenia and pre-diagnosis of MDS in 2015 and 78 patients (20\%) were pathologically diagnosed with MDS. Patients were reassessed with a scoring system in which four parameters were combined with the flow cytometer: Increased myeloblast ratio (ratio $>2 \%$ of $C D 34+$ ), decreased CD34+B progenitor ratio (less than $5 \%$ of total CD34+cells), increase or decrease in lymphocyte proportion to CD45 expression $(<4,>7.5)$ and decrease in $90^{\circ}$ light distribution in granulocytes (granulocyte/lymphocyte SSC ratio $<6$ ). A score of 2 and above supports the diagnosis of MDS. Chi-square test was used in the analysis of categorical variables.

Results: The median age of 78 patients was 62 . In low-risk patients (45\%) in the absence of specific markers of bone marrow dysplasia (eg ring sideroblast and/or clonal chromosomal abnormalities), the Ogata score was two or higher. It was found that patients with high Ogata score (Score 3 or 4$)$ were transfusion dependent $(p=0.021)$ and had a higher WPSS score $(p=0.002)$.

Conclusion: Flow cytometric Ogata scoring can be used as a diagnostic method for MDS.

Key Words: Myelodysplastic syndrome; Flow cytometry; Ogata scoring

\section{GíRiş}

Miyelodisplastik sendrom (MDS), hematopoietik kök hücrelerden kaynaklanan inefektif hematopoiesis ile seyreden heterojen klonal bir hastalık grubudur. Kemik iliği displazisi akut miyeloid lösemiye dönüşebilir. Hastaların klinik prognozlarını belirlerken ve tedavi planlaması yapılırken kemik iliği blast yüzdesi, sitopeniler ve karyotipi içeren bir skorlama sistemi olan International Prognostic Scoring System (IPSS) kullanmaktadır. 2012 yılında yapılan revizyonla R-IPSS skorlama sistemiyle hastalar sağ kalımlarına ve hastalıklarının AML'ye dönüşme risklerine göre 5 risk grubuna ayrılmışlardır (1,2). Buna göre R-IPSS skoru ${ }^{3} 4$ olanlar daha yüksek riskli hastalar olarak değerlendirilmiştir. Özellikle R-IPSS'e göre düşük riskli olan hastalarda özgün tanısal kriterler saptanamayacağından tanı koymak zordur.

Akan hücre ölçer, pek çok hematolojik hastalığın tanı/ takibinde kullanılan güvenilir bir yöntemdir (3). Birçok çaıışma, akan hücre ölçer kullanımının MDS'de tanıdaki etkinliğini değerlendirmiştir (4-6). MDS tanısını destekleyecek tek bir immünofenotipik belirteç bulunmamaktadır. Ogata ve arkadaşları Akan hücre ölçer (Flow Cytometry, FCM) ile MDS'ye özgün olan biyolojik özellikleri gösteren 4 parametreli bir skorlama sistemi geliştirmiştir (7). Buna göre miyeloblast oranının çekirdekli hücrelerin \%2'sinden fazla olması, azalmış CD34+ B progenitör oranı (Total CD34 + hücrelerin \%5'inden az), Lenfositlerinki ile karşılaştırıldığında CD45 ifadesinde azalma ya da artma (oran: < 4, > 7.5) ve granülositlerin verdiği $90^{\circ}$ ışık dağılımında azalma (granulosit/lenfosit SSC oranı < 6) MDS'nin tanısında kullanılır. Birçok merkezde valide edilmiş bu skorlama sistemi ile özellikle düşük dereceli MDS, klonal olmayan sitopenilerden ayrılabilmektedir (8). Bu çalışmadaki amacımız, patolojik olarak MDS tanısı alan hastaların geriye dönük olarak tekrar FCM ile değerlendirilmesi ve FCM skorlama sisteminin etkinliğinin özellikle düşük dereceli MDS'de gösterilmesidir.

\section{HASTALAR ve YÖNTEM}

Ocak-Kasım 2015 tarihleri arasında merkezimize başvuran ve sitopenisi olan 386 hastaya MDS ön tanısıyla onamları alındıktan sonra kemik iliği biyopsisi yapılmış ve 78 hasta (\%20) patolojik olarak MDS tanısı almıştır. Hastaların MDS alt tipleri Dünya Sağlık Örgütü 2016 güncel MDS sınıflamasına göre revize edilmiştir (9). Hastalar R-IPSS'e ve WPSS'e göre sınıflandırılmıştır (2).

Hastalar kemik iliği aspiratının akım sitometrik olarak dört parametrenin kombine edildiği Ogata skorlama sistemi ile geriye dönük olarak yeniden değerlendirilmiştir. Artmış CD34+ myeloblast oranı (\% $\geq 2$ ) 1 puan; CD34+ hücreler arasında azalmış CD34+ B progenitör oranı $\% \leq$ 5) 1 puan; Lenfosit/Myeloblast CD45 ifadesi (MFI oranı $\leq 4$ veya $\geq 7.5$ olması 1 puan; Granülosit/Lenfosit SSC oranının $\leq 6$ olması 1 puan olarak değerlendirilmiştir. Bu skorlama sistemine göre skoru 2 ve üzerinde bulunan olgular pozitif olarak değerlendirilip MDS tanısını destekleyen bir özellik olarak kaydedilmiştir

Tüm sayısal veriler ortanca ve ölçüm aralığı olarak verilmiştir. Kategorik değişkenlerin karşılaştırılmasında Pearson ki-kare testi veya Fisher exact testi kullanılmıştır. $p<0.05$ olması istatistiksel olarak anlamlı kabul edilmiştir. İstastiksel analizde SPSS 20.0 yazılımı kullanılmıştır.

\section{BULGULAR}

78 hastanın median yaşı 62'dir (aralık, 18-90), 49 hasta (\%62) erkektir. Çalışmaya alınan hastaların MDS alt tip dağılımları şöyle özetlenebilir: Olguların 26'sı (\%33) tek seri displazisi ile birlikte olan MDS, 8'i (\%10) halka (ring) sideroblastlar ile birlikte tek seri displazisi, 18'i (\%24) çok seride displazi ile beraber olan MDS, 7'si (\%9) artmış blast sayılı MDS alt grup 1, 19'u (\%24) artmış blast sayılı MDS alt grup 2. Hastalar R-IPSS'e göre değerlendirildiklerinde 15'i (\%19) tanı anında çok düşük riskli, 21'i (\%27) düşük riskli, 16'sı (\%21) orta riskli, 15'i (\%19) yüksek riskli, 11'i (\%14) ise çok yüksek risklidir. WPSS'e bakıldığında ise 14 hasta (\%18) çok düşük riskli, 25 hasta (\%32) düşük riskli, 8 hasta (\%10) orta riskli, 18 hasta (\%23) yüksek riskli, 13 hasta (\%17) ise çok yüksek risklidir. Hasta özellikleri Tablo 1'de özetlenmiştir. Hastaların karyotip analizlerinde 48 hastada (\%61) normal karyotip, 17 hastada (\%22) bir kromozomal anomalisi, 4 
Tablo 1. Çalışmaya katılan hastaların özellikleri $(n=78)$

$\begin{array}{ll}\text { Ortanca yaş (yıl) } & 62 \text { (aralık, 18-90) } \\ \text { E/K (n,\%) } & 49(\% 62) / 29(\% 38) \\ \text { MDS alt tipi (n,\%) } & \\ \text { Tek seri displazisi ile birlikte olan MDS } & 26(\% 33) \\ \text { Halka (ring) sideroblastlar ile birlikte tek seri displazisi } & 8(\% 10) \\ \text { Çok seride displazi ile beraber olan MDS } & 18(\% 24) \\ \text { MDS blast artışı alt grup 1 } & 7(\% 9) \\ \text { MDS blast artışı alt grup 2 } & 19(\% 24) \\ \text { R-IPSS (n,\%) } & \\ \text { Çok düşük } & 15(\% 19) \\ \text { Düşük } & 21(\% 27) \\ \text { Orta } & 16(\% 21) \\ \text { Yüksek } & 15(\% 19) \\ \text { Çok yüksek } & 11(\% 14) \\ \text { WPSS (n,\%) } & \\ \text { Çok düşük } & 14(\% 18) \\ \text { Düşük } & 25(\% 32) \\ \text { Orta } & 8(\% 10) \\ \text { Yüksek } & 18(\% 23) \\ \text { Çok yüksek } & 13(\% 17)\end{array}$

hastada (\%5) iki kromozomal anomalisi saptanırken, 9 hastada (\%12) kompleks karyotip tespit edilmiştir. Sitogenetik anomaliler Tablo 2'de detaylı olarak sunulmuştur. Hastaların 34'üne (\%44) tedavi verilmezken, 15 hasta (\%19) eritropoietin ve/veya filgrastim, 23 hasta (\%29) azasitidin, 6 hasta talidomid/danazol almıştır. Tedavi verilen 44 hastadan kısmi veya tam yanıt alınan 34 hasta (\%77) vardır. Hastaların hiçbirine allojeneik kök hücre nakli uygulanmamıştır.

Hastaların Ogata ve arkadaşlarının önerdiği FCM skorları geriye dönük olarak tekrar hesaplandığında 78 hastanın 44'ünde (\%56) skor 2 veya üzerinde bulunmuştur. Hastaların 14'ünde (\%18) skor 2, 19 hasta (\%24) skor 3, 11 hasta (\%14) skor 4 olarak saptanmıştır. Kemik iliği displazisinin özgün göstergelerinin (örn. Ring sideroblast ve/veya klonal kromozomal anormallikler) olmadığı düşük risk hastalarda Ogata skoru \%45 hastada iki veya üzerindedir. Ogata skoru pozitif ve negatif saptanan hastaların özellikleri Tablo 3'te karşılaştırılmıştır. Ogata skoru pozitif olan hastalar negatif olanlara göre R-IPSS skoru orta/yüksek veya çok

\section{Tablo 2. Hastaların sitogenetik anomalileri}

\begin{tabular}{lc} 
Sitogenetik Anomaliler & $\mathbf{N}(\%)$ \\
\hline$-Y$ & $2(\% 2)$ \\
$17 p-$ & $4(\% 5)$ \\
$5 q^{-}$ & $4(\% 5)$ \\
$20 q-$ & $1(\% 1)$ \\
$7 q-$ & $1(\% 1)$ \\
+8 & $5(\% 6)$ \\
+19 & $1(\% 1)$ \\
-7 & $15(\% 30)$
\end{tabular}

yüksek ( $p=0.02)$, WPSS skoru orta/yüksek veya çok yüksek $(p=0.01)$ ve daha fazla transfüzyon bağımlısıdır $(p=0.03)$. Alt grup analizinde, Ogata skoru yüksek (3 veya 4) olan hastalar daha fazla transfüzyon bağımlısıdır $(p=0.021)$ ve daha yüksek WPSS skoruna sahiptirler $(p=0.002)$.

\section{TARTIŞMA ve SONUÇ}

MDS, erken dönemde hiçbir özelliğin görülmediği hastalardan halka sideroblast, artmış blast ve/veya sitogenetik anomalileri de içine alan çok geniş spektrumda değerlendirilmesi gereken hastalık grubudur (1). Blast artışı, ring sideroblast varlığı ve/veya sitogenetik anomali mevcut ise MDS tanısı klinisyen tarafından kolayca konulabilir. Fakat bu özelliklerin bulunmadığı düşük dereceli MDS'de tanı koymak zordur (10). MDS'de patolojik değerlendirmedeki temel özellik kemik iliği displazisidir fakat morfolojik olarak bu özellik klonal olmayan sitopenilerde de bulunmaktadır (9).

Çok parametreli akan hücre ölçer, hematolojide birçok hastalığın tanısı, risk gruplarının belirlenmesi ve tedavi yanıtının değerlendirilmesinde rol oynar. Kemik iliği displazisinin akan hücre ölçer aracılığı ile değerlendirilmesi MDS tanısındaki duyarlılığı arttırmada potansiyel bir tanı yöntemi olarak kullanılabilir. Bu amaçla belirlenmiş akan hücre ölçer skorlama sistemleri geliştirilmiştir. Genel olarak yüksek skorlar tanı açısından daha duyarlıdır ve hastalar yüksek lösemik transformasyon riski gösteriler (11). Stetler-Stevenson ve arkadaşları ilk olarak yayınladıkları skorlama sistemi sonrasında birçok farklı parametreleri akan hücre ölçer skorlama sistemleri geliştirilmesine rağmen, belirlenmiş parametrelerden çoğunun duyarlılığı ve 
Tablo 3. Ogata (FCM) skoru pozitif ve negatif hasta özellikleri

\begin{tabular}{|c|c|c|c|}
\hline & $\begin{array}{l}\text { Ogata (FCM) skoru pozitif } \\
\qquad(n=44)\end{array}$ & $\begin{array}{l}\text { Ogata (FCM) skoru negatif } \\
\qquad(n=34)\end{array}$ & $\mathbf{P}$ \\
\hline Ortanca yaş (yaş \pm standart sapma) & $61.9 \pm 17.09$ & $61.6 \pm 16.39$ & 0.71 \\
\hline \multicolumn{4}{|l|}{ MDS alt tipi (n, \%) } \\
\hline Tek seri displazisi ile MDS & 12 & 14 & \\
\hline Halka (ring) sideroblastlar ile birlikte tek seri displazisi & 5 & 3 & 0.69 \\
\hline Çok seride displazi ile beraber olan MDS & 10 & 8 & \\
\hline MDS blast artışı alt grup 1 & 5 & 2 & \\
\hline MDS blast artışı alt grup 2 & 12 & 7 & \\
\hline \multicolumn{4}{|l|}{ R-IPSS (n, \%) } \\
\hline Çok düşük/düşük & $15(\% 34)$ & $21(\% 62)$ & 0.02 \\
\hline Orta/yüksek/çok yüksek & $29(\% 66)$ & $13(\% 38)$ & \\
\hline \multicolumn{4}{|l|}{ WPSS ( $n, \%)$} \\
\hline Çok düşük/düşük & $16(\% 36)$ & $23(\% 68)$ & 0.01 \\
\hline Orta/yüksek/çok yüksek & $28(\% 64)$ & $11(\% 32)$ & \\
\hline Transfüzyon bağımlılığı (n, \%) & $30(\% 68)$ & $15(\% 44)$ & 0.03 \\
\hline
\end{tabular}

özgüllüğü klinik tanı için yeterli değildir (12-14). Ogata ve arkadaşları MDS tanısında kullanılabilecek FCM skorlama sistemini geliştirmişlerdir. Bu skorlama sisteminde MDS'ye ait özellikler dört ana başlık altında toplanmıştır. Bu başlıklar; CD34 pozitif myeloid hücre artışı, B hücre progenitörlerinde azalma, granülosit lenfosit SSC oranının azalması, anormal CD45 ekpresyonudur. 2009'da ilk değerlendirme çalışması sonrasında (7) 4 parametreye bağlı validasyon çalışması 2012'de çok merkezli olarak gerçekleştirilmiştir (8). Skorlama sisteminin en önemli özelliği FCM ile tanısal amaçlı çalışmaların tümünde yaygın olarak yer alan antikorlar kullanarak maliyet açısından avantaj sağlamasıdır. Çok merkezli validasyon çalışmasında Ogata ve arkadaşları geliştirdiği FCM skorlama sistemiyle 281 hastanın 198'ine MDS tanısı konmuştur (duyarlılık \%70) (8). Farklı bir çalışmada, klinik olarak MDS'den şüphenilen 35 hastadan 32'si (\%91) FCM skorlama sistemi ile doğrulanmıştır (15). Bizim çalışmamızda geriye dönük olarak değerlendirilen 78 hastanın 44'ünde (\%56) akım sitometrik olarak FCM skoru pozitif olarak saptanmıştır. Özellikle displazinin spesifik göstergelerinin olmadığı hasta grubunda \%65 hastada MDS tanısı konurken (8) çalışmamızda bu oran \%45'tir.

Çalışmamıza alınan hastalarda Ogata skoru pozitif olan hastalar negatif olanlara göre R-IPSS skoru orta/yüksek veya çok yüksek $(p=0.02)$, WPSS skoru orta/yüksek veya çok yüksek ( $p=0.01)$ ve daha fazla transfüzyon bağımlısıdır $(p=0.03)$. Alt grup analizinde ise yüksek Ogata skoru (3 veya 4) olan hastalar daha fazla transfüzyon bağımlısıdır $(p=0.021)$ ve daha yüksek WPSS skoruna sahiptirler $(p=$ 0.002). Çalışmamıza paralel olarak Della Porta ve arkadaşlarının 258 Fransız ve Japon hastanın dahil edildiği bir çalışmasında Ogata skoru 2 ve üstünde olan hastalarda daha fazla transfüzyon bağımlılığı $(p<0.001)$ ve yüksek R-IPSS skoru gösterilmiştir $(p<0.001)(16)$. Ayrıca hastalarda daha ciddi sitopeni $(p=0.04)$ ve daha fazla çoklu seri displazisi $(p<0.001)$ raporlanmıştır. Bizim çalışmamızda MDS alt grupları ile skorlama sistemi arasında istatistiksel olarak anlamlı fark saptanmamıştır.

Sonuç olarak, Ogata ve arkadaşları geliştirdiği akan hücre ölçer ile belirlenen FCM skoru özellikle morfolojik ve sitogenetik özellikleriyle tanısı zor konan MDS hastalarında tanıyı kolaylaştıracak bir yöntem olarak klinik tanıya yardımcı olarak kullanılabilir.

\section{ETIK KURUL ONAYI}

Çalışma retrospektif olduğu için Ankara Üniversitesi Tıp Fakültesi İç Hastalıkları Anabilim Dalı, Hematoloji BD'den 07.09.2020 tarihinde Akademik Kurul kararı ve onayı alınmıştır.

\section{ÇIKAR ÇATIŞMASI}

Yazarların çıkar çatışması bulunmamaktadır.

\section{MALI AÇIKLAMA}

Çalışma için doğrudan veya dolaylı mali destek alınmadı. Çalışma ile ilgili herhangi bir firma veya kişi ile ilgili ticari bağlantı yoktur.

\section{YAZAR KATKISI}

Literatür taranması: EA, PAA; Hasta takibi ve değerlendirilmesi: EA, PAA, SCB, SKT, HA, MB, ÖA, PT, MÖ, OI, HIR, IK, GG, KD; Verilerin Toplanması: EA, EK, PAA; Makalenin Yazımı: EA, PAA; Onaylama: SCB, SKT, HA, MB, ÖA, PT, MÖ, Oİ, HIR, IK, GG, KD.

\section{KAYNAKLAR}

1. Greenberg P, Cox C, LeBeau MM, Fenaux P, Morel P, Sanz G, et al. International scoring system for evaluating prognosis in myelodysplastic syndromes. Blood. 1997;89:2079-88. 
2. Greenberg PL, Tuechler H, Schanz J, Sanz G, Garcia-Manero G, Solé $F$, et al. Revised international prognostic scoring system for myelodysplastic syndromes. Blood. 2012;120:2454-65.

3. Craig FE, Foon KA. Flow cytometric immunophenotyping for hematologic neoplasms. Blood. 2008;111(8):3941-67.

4. Della Porta MG, Malcovati L, Invernizzi R, Travaglino E, Pascutto C, Maffioli M, et al. Flow cytometry evaluation of erythroid dysplasia in patients with myelodysplastic syndrome. Leukemia. 2006;20(4):549-55.

5. Malcovati L, Della Porta MG, Lunghi M, Pascutto C, Vanelli L, Travaglino $E$, et al. Flow cytometry evaluation of erythroid and myeloid dysplasia in patients with myelodysplastic syndrome. Leukemia. 2005;19(5):776-83.

6. Van de Loosdrecht AA, Westers TM, Westra AH, Drager AM, van der Velden $\mathrm{VH}$, Ossenkoppele GJ. Identification of distinct prognostic subgroups in low- and intermediate-1-risk myelodysplastic syndromes by flow cytometry. Blood. 2008;111(3):1067-77.

7. Ogata K, Della Porta MG, Malcovati L, Picone C, Yokose N, Matsuda A, et al. Diagnostic utility of flow cytometry in low-grade myelodysplastic syndromes: a prospective validation study. Haematologica. 2009;94(8):1066-74.

8. Della Porta MG, Picone C, Pascutto C, Malcovati L, Tamura H, Han$\mathrm{da} \mathrm{H}$, et al. Multicenter validation of reproducible flow cytmetric score for the diagnosis of low-grade myelodysplastic syndromes: results of a European LeukemiaNET study. Haematologica. 2012;97(8):1209-17.

9. Arber DA, Orazi A, Hasserjan R, Thiele J, Borowitz MJ, Le Beau MM, et al. The 2016 revision to the World Health Organization classification of myeloid neoplasms and acute leukemia. Blood. 2016;127(20):2391-405.
10. Ramos F, Fernandez-Ferrero S, Suarez D, Barbon M, Rodriguez JA, Gil S, et al. Myelodysplastic syndrome: a search for minimal diagnostic criteria. Leuk Res. 1999;23(3):283-90.

11. Wells DA, Benesch M, Loken MR, Vallejo C, Myerson D, Leisenring WM, et al. Myeloid and monocytic dyspoiesis as determined by flow cytometric scoring in myelodysplastic syndrome correlates with the IPSS and with outcome after hematopoietic stem cell transplantation. Blood. 2003;102:394-403.

12. Stetler-Stevenson M, Arthur DC, Jabbour N, Xie XY, Molldrem J, Barrett AJ, et al. Diagnostic utility of flow cytometric immunophenotyping in myelodysplastic syndrome. Blood. 2001:98:979.

13. Van de Loosdrecht AA, Alhan C, Bene MC, Della Porta MG, Drager AM, Feuillard J, et al. Standardization of flow cytometry in myelodysplastic syndromes: report from the first European LeukemiaNet working conference on flow cytometry in myelodysplastic syndromes. Haematologica. 2009;94(8): 1124-34.

14. Maecker HT, McCoy JP Jr, Amos M, Elliott J, Gaigalas A, Wang L, et al. A model for harmonizing flow cytometry in clinical trials. Nat Immunol. 2010;11(11):975-8.

15. Matzen SMH, Raaschou-Jensen KK, Kallenbach K. Implementation of the Ogata flow cytometric scoring system in routine diagnostics of myelodysplastic syndrome. Health Sci Rep. 2018 Nov;1(11):e90.

16. Della Porta MG, Picone C, Tenore A, Yokose N, Malcovati L, Cazzola $M$, et al. Prognostic significance of reproducible immunophenotypic markers of marrow dysplasia. Haematologica. 2014;99:e8-e10. 